\title{
Temporal changes in atmospheric water content during the December 2004 Sumatra earthquake as estimated from GPS signals and its possible connection to the January 2005 California flash flood
} \author{
Harald Schuh ${ }^{2}$ \\ ${ }^{1}$ CSIR-National Geophysical Research Institute, Hyderabad, India \\ 2 GFZ, Potsdam, Germany \\ Article history \\ Received October 27, 2017; accepted December 21, 2017. \\ Subject classification: \\ Troposphere; ZTD; GPS-Meteorology; 2004 Sumatra earthquake; PWV.
}

Athiswamy Nadar Akilan ${ }^{1,}$, Kizhakkekara Kunjavaran Abdul Azeez ${ }^{1}$, Simanchal Padhy ${ }^{1}$,

\begin{abstract}
We studied the temporal change in Zenith Total Delay (ZTD) from the GPS signals received at sites around the epicentral region of the 26 December 2004 Great Sumatra earthquake (Mw 9.0). The estimated ZTD values at the nearest GPS locations available around the earthquake region showed a significant rise after the earthquake at locations to its east ( $\sim 63 \mathrm{~mm}$ at NTUS) and south ( $110 \mathrm{~mm}$ at COCO), but no changes were seen towards the west. The increase in ZTD (and thus precipitable water vapor, $P W V$ ) associated to the earthquake process is attributed to the thermal energy released through the earthquake process and the probable heat induced on to the ocean surface through the magma upwelling processes in the earthquake region, which all might have caused increase in ocean water temperature and catalyzed the evaporation process yielding high precipitation over the region. However, this high precipitation did not produce rainfall in its vicinity and appears to have moved to the California coast by the subtropical jet stream present over the region during this period. The southern California experienced a historical heavy rain from $28^{\text {th }}$ of December, 2004 to $12^{\text {th }}$ of January, 2005 and the El Niño conditions in the Pacific Ocean alone could not explain such an unusual high pre cipitation in the winter period. We conclude that the severe weather conditions over the Californian coast and resulting flash flood might have been caused by transport of high water vapor formed over the Sumatra earthquake epicentral region to the California coast by the subtropical jet stream movement from west to east.
\end{abstract}

\section{Introduction}

Earthquake is the natural process through which the subsurface strain energy, accumulated over time due to various earth geodynamic processes is released [Aki 1971, McNamara et al. 2016]. A strong earthquake can caused significant subsurface structure changes and surface deformations [Burgmann et al. 2000, Larson et al. 2003, 2009]. In addition to such noticeable changes on the earth, the earthquake phenomena also influence the dynamics of the overlying atmosphere with enhancement in atmospheric temperature [Tronin et al. 2002, Pulinets et al. 2006] and perturbation in the Total Electron Content (TEC) of the ionosphere [Calais and Minister 1995, Afraimovich et al. 2001, Ducic et al. 2003, Liu et al. 2010, Catherine et al. 2017]. Recently, studies have also inferred notable changes in atmospheric water content connected to seismogenic processes [Akilan et al. 2016, 2017].

The Global Positioning System (GPS) technology [Leick 1990], which was originally designed as a system for navigation and time transfer, is extensively used in geodynamic and earthquake studies due to its capability to provide precise geodetic positions with little costs. The GPS monitoring also finds useful role in meteorological studies [Businger et al. 1996] as the Zenith Total Delay (ZTD) experienced by the GPS signal is chiefly affected by the atmospheric water content [Bevis et al. 1992]. Moreover, GPS signals are analysed to study the Total Electron Content (TEC) over the ionosphere, one of the important parameters explaining the dynamics of the atmosphere, as the TEC is found to be a precursor for short-term earthquake prediction [Heki 2011]. Thus, the analysis of the GPS signals recorded on the earth surface has been widely and effectively used for identification and quantification of earth deformation, meteorological studies and changes in atmospheric parameters which are accompanying seismic events [Ouzounov 2011, Heki and Enomoto, 2013; Wang et 
al., 2013; Akilan et al., 2015; Catherine et al., 2017; Akilan et al. 2017]. In this study, we evaluate the changes in atmospheric water content during the large magnitude (Mw 9.0) 26th of December, 2004, Sumatra earthquake in the Indian Ocean region and explore its possible link to the occurrence of heavy rainfall at the west coast of California (North America) in the month of January 2005.

\section{The 2004 Great Sumatra (Mw 9.0) Earthquake}

The Great Sumatra earthquake on 26th December, 2004 at 00:58:53 hrs has caused severe damages in the countries around the Indian Ocean [Vigny et al. 2005, Ohta et al. 2006, Paul et al. 2007]. The Mw 9.0 Sumatra earthquake occurred from the subduction zone initiated near the coast of northern Sumatra (Ammon et al., 2005). No significant foreshock activity was reported prior to the major event, but several aftershock events of swarm nature were recorded. Figure 1 shows the swarm events with magnitude 6 and above. Such earthquake swarms are in general associated with magma movement in the subsurface [Karpin and Thurbar 1987]. Although the main seismic event in the region is considered to be of tectonic origin [Lay et al. 2005], the subsequent swarm activity could have a volcano-tectonic origin [Karpin and Thurbar 1987, Walter and Amelung 2007]. Subaerial and submarine volcanoes occur along Sumatra and Andaman Islands and in their surroundings, which result from the ongoing subduction of the Indo-Australina plate under the Sunda plate [Walter and Amelung 2007]. Volcano-tectonic seismic events associated with the magma injections at the upper crustal depths and/or eruptions onto the ocean surface were identified in the Andaman region [Kundu et al. 2012, Akilan et al. 2017]. The seismic swarm like events, particularly the $M>5$ earthquakes, occurred soon after the 2004 Sumatra event to the north of epicentre are possibly indicating sub-marine volcanic activity in the region [Walter and Amelung 2007].

\section{Precipitated Water Vapor}

The GPS meteorology makes use of the delay caused to the GPS signals during its passage through the troposphere while travelling from the satellite transmitter in space to the GPS signal receiver on earth. This delay caused by the troposphere known as Zenith Total Delay (ZTD) is directly related to the constituent components of the troposphere, namely the wet water vapor and dry gaseous components in the troposphere [e.g. Nilsson and Elgered 2008, Wang et al. 2013]. The delay contribution from the wet component, which is controlled by the atmospheric water content, is called the Zenith Wet Delay (ZWD) and the delay due to dry gaseous components in the troposphere is called the Zenith Hydrostatic Delay (ZHD). Since the ZWD is due to the water vapor present in the atmosphere, the precipitable water $\left(P_{w}\right)$ can be estimated from ZWD as [Nilsson 2013]:

$$
P_{w}=k \Delta L_{w}^{z}
$$

where $\Delta L_{w}^{z}$ is the ZWD, that can be expressed as,

$$
\Delta L_{W}^{Z}=\frac{10^{6} M_{w}}{\left[k_{2}^{\prime}+k_{3} / T_{m}\right] R_{w l}}
$$

where $k_{2}=16.52 \mathrm{~K} / \mathrm{mbar}$, and $k_{3}=3776 \pm 0.004 \times 10^{5}$ $\mathrm{K}^{2} / \mathrm{mbar}$ are the constants [Askne and Nordius 1987], $M_{w}$ is the molar mass of water $(18.0152 \mathrm{~g} / \mathrm{mol}), T_{m}$ is the mean temperature $\approx 70.2+0.72 T_{0}$, where $T_{0}$ is the Earth surface temperature, $R$ is the universal gas constant $(R=8.314 \mathrm{~J} / \mathrm{mol})$, and $\rho_{w l}$ is the density of liquid water in $\mathrm{kg} / \mathrm{m}^{3}$.

\section{GPS data during the 2004 Sumatra earthquake and processing}

We analyzed GPS data from the network of IGS (International Global Navigation Satellite Systems Service) stations and finally derived ZTD at two stations, COCO and NTUS, which are relatively close to the 2004 earthquake source locations. The two GPS sites are located $\sim 800$ and $\sim 1725 \mathrm{~km}$ away from the main shock epicentre. The main shock (Mw 9.0) occurred on 26th December, 2004 (GPS Day 361) at 3.316 N 95.854 E off the west coast of northern Sumatra at 00:58 Hrs. The GPS data for a period of 11 days (GPS day from 355 to 365) during the occurrence of the 2004 earthquake are analyzed to understand the atmospheric changes induced by the earthquake process.

The GPS data were processed using Bernese software [Dach et al. 2007]. In the processing, precise orbit files and ionosphere-free linear combination of the L1 and L/2 carrier wave frequency to overcome ionosphere delay were used. The elevation mask for the antenna was set to $5^{\circ}$. The stations used here for processing the GPS data are Bakosurtanal (BAKO), Cocos (COCO), Diego Garcia Island (DGAR), Hartebeesthoek (HARB), Hyderabad (HYDE), Indian Institute of Science (IISC), Irkutsk (IRKT), Kitab (KIT3), Nanyang Technological University (NTUS), Poligan Ivtan 2 (POL2), Braunschweig (PTBB), Republic of Seychelles permanent (SEY1), Shanghai Astronomical Observatory (SHAO), and Yaragadee (YAR2). Table 1 lists the stations used for the data analyses. This data processing strategy helps us to get more accurate results for better understanding the troposphere behaviour induced by the large earth- 


\begin{tabular}{lccccc}
\hline Station Name & City & Country & Tectonic plate & Lat (Deg) & Long (Deg) \\
\hline COCO & Cocos (Keeling) Island & Australia & Australian & -12.18 & 96.83 \\
NTUS & Singapore & Singapore & Eurasian & 01.34 & 103.67 \\
HYDE & Hyderabad & India & Indian & 17.42 & 78.55 \\
IISC & Bangalore & India & Indian & 13.02 & 77.57 \\
DGAR & Diego Garcia Island & United Kingdom & Australian & -7.27 & 72.37 \\
YAR2 & Yarragadee & Australia & Australian & -29.05 & 115.35 \\
JPLM & Pasadena & United States & Pacific & 34.20 & -118.17 \\
\hline
\end{tabular}

Table 1. The station location used for analysis.

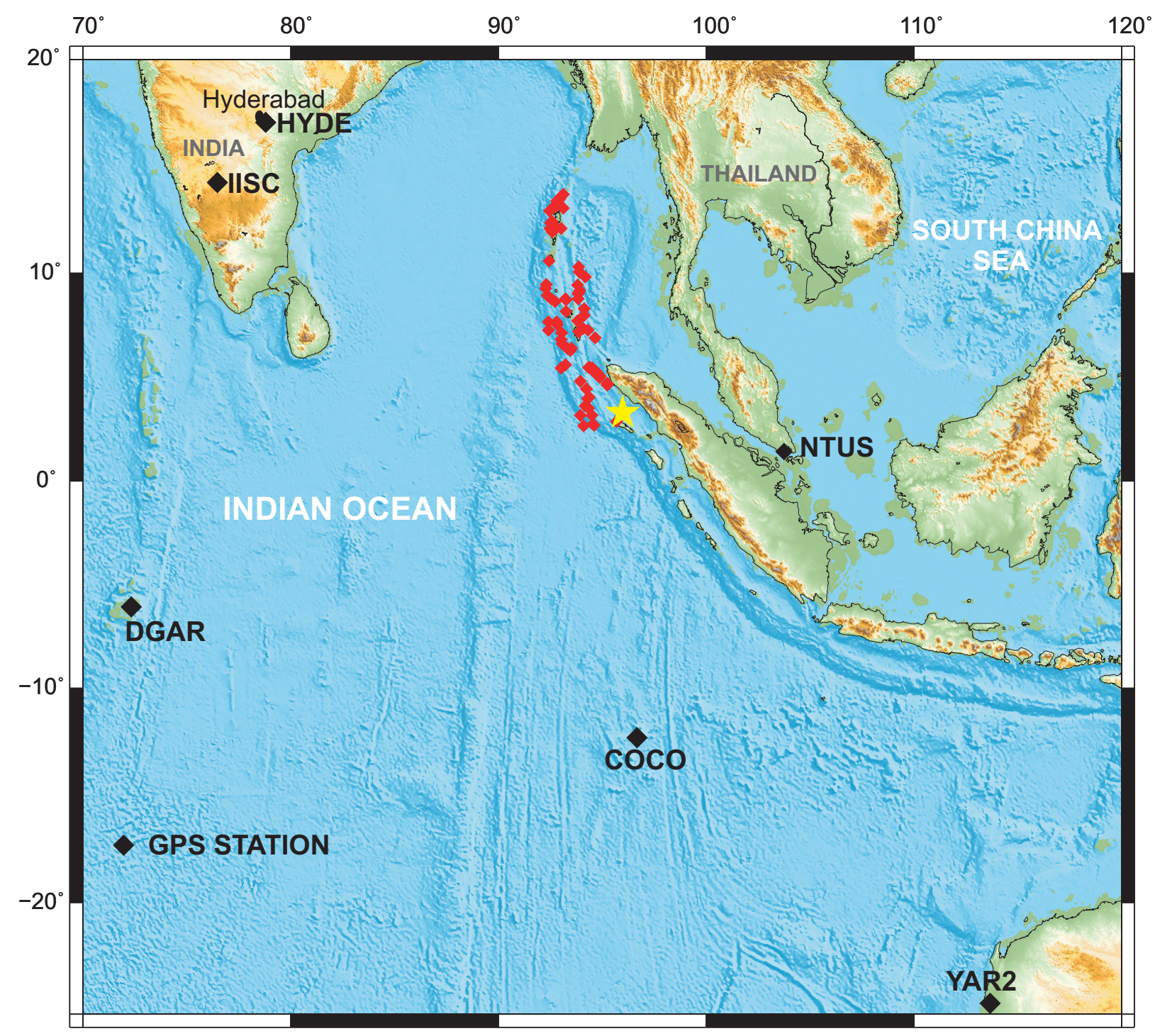

Figure 1. GPS stations (black diamond symbol) considered in the study shown over the topography map of SE Asia and the Indian Ocean region. The yellow star represents the epicentre of the 2004 Great Sumatra earthquake and red symbols represent the aftershock events of magnitude 6.0 and above. 

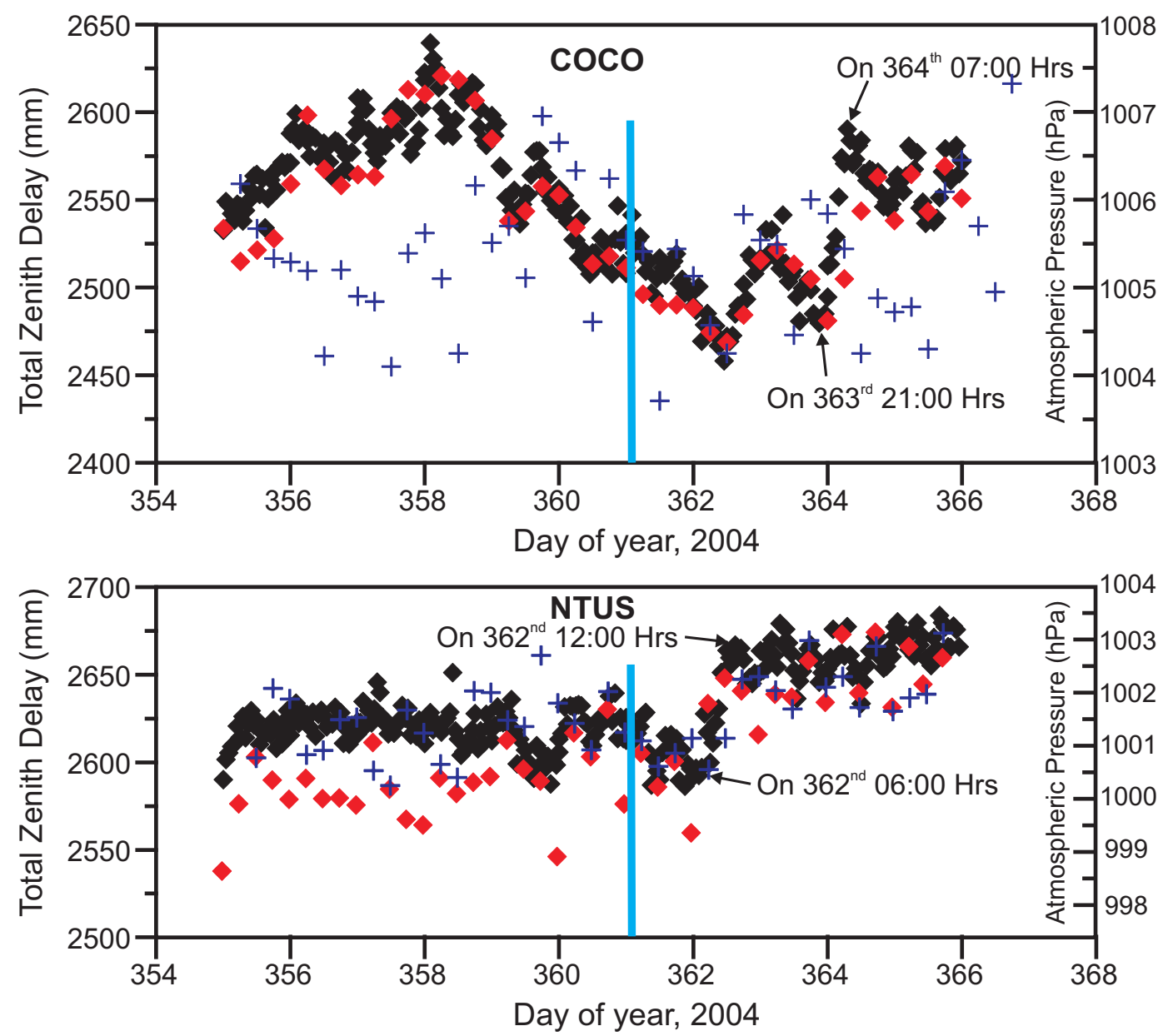

Figure 2. Comparison between the GPS-derived (black diamond) and NWM (red diamond) Total Zenith Delay (ZTD) values at COCO (top) and NTUS (bottom) during the time of the 2004 great Sumatra earthquake event, which is shown by thick blue line. Atmospheric pressure variation (blue plus symbols) over the GPS sites, obtained from NWM (http: / /www.ecmwf.int), is also plotted.

quake. The data during the GPS days of 355 to 365 of the year 2004 (11 days) were analysed and processed to compute the hourly ZTD values for the above period.

\section{Results and discussion}

The values of ZTD estimated at the IGS GPS stations NTUS and COCO (Figure 2), which are located in the vicinity and to the east and south of the 2004 Sumatra earthquake epicenter (Figure 1), show increase following the 2004 earthquake main shock. At COCO, its value increased by $\sim 111 \mathrm{~mm}$ from $2479.7 \mathrm{~mm}$ to 2590.4 mm during the GPS day of 363:21 hrs to 364:07 hrs, while at the station NTUS, its value increased by $\sim 64 \mathrm{~mm}$ from $2600.6 \mathrm{~mm}$ to $2664.1 \mathrm{~mm}$ during the GPS day of $362: 06 \mathrm{hrs}$ to $362: 12 \mathrm{hrs}$ (Figure 2). At COCO, which is at $\sim 1725 \mathrm{~km}$ south of the epicentre zone, high ZTD values occurred prior to the earthquake event. The ZTD estimated from both the GPS and numerical weather modelling (NWM) [Boehm et al. 2006, Bock et al. 2014] published by the European Centre for Medium Weather Forecasting (ECMWF) [http:/www.ecmwf.int/] (Figure 2) are in good agreement with each other, suggesting the estimates as more reliable. However, the sites located to the west of earthquake region did not show any noticeable change in ZTD values during the earthquake period (Figure 3 ).

The ZTD increase noticed over the COCO station from GPS day 363 at 21:00 hrs ( $68 \mathrm{hrs}$ after the 2004 main shock) and NTUS from GPS day 362 at 06:00 hrs ( $\sim 29$ hrs after the mainshock) directly indicates high precipitation in the atmosphere over the region. The estimated precipitable water vapor (PWV) from the observed ZTD values using the equation (1). The ZHD values required to compute the ZWD component from the ZTD were taken from the NWM computed values available the GPS sites. The GPS estimated ZTD and the PWV values show good agreement (Figure 4). This good correspondence between the ZTD and PWV was also verified from the correlation between GPS estimated ZTD and PWV, which showed high correlation coefficient values of 0.98438 and 0.831299 , respectively, for the sites NTUS and COCO. Since the earthquake process involves huge release of energy, which also includes significant thermal radiations that chiefly accompany major earthquakes [Pulinets 2003, Ouzounov and Freund 2004, Saraf and Choudhury 2005, Pulinets 


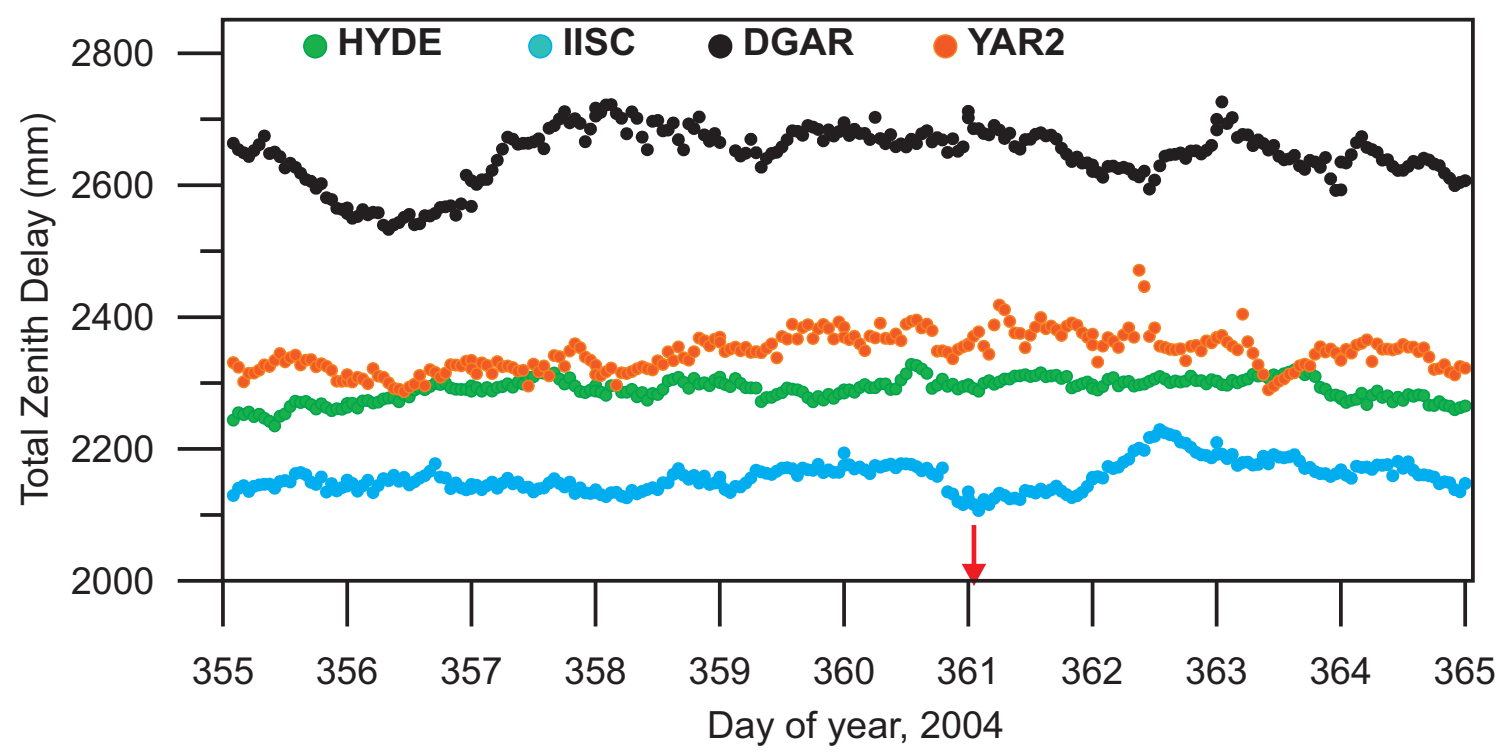

Figure 3. GPS-derived Total Zenith Delay (ZTD) values at locations to the west and far south of the 2004 great Sumatra earthquake epicentral zone. HYDE: Hyderabad (India); IISC: Indian Institute of Science, Bangalore (India); DGAR; Diego Garcia (Indian Ocean); YAR2: Yaragadee (Australia). The red arrow represents the earthquake origin time.

2006, Yuan-Sheng 2011], the increase in ZTD (PWV) coinciding with the earthquake could be due to accelerated evaporation process by the additional thermal energy release through the earthquake process. In the case of Sumatra region, the main earthquake and most of the subsequent aftershocks are focused to the marine environment. Thus, the thermal energy released and the probable heat induced on to the ocean surface
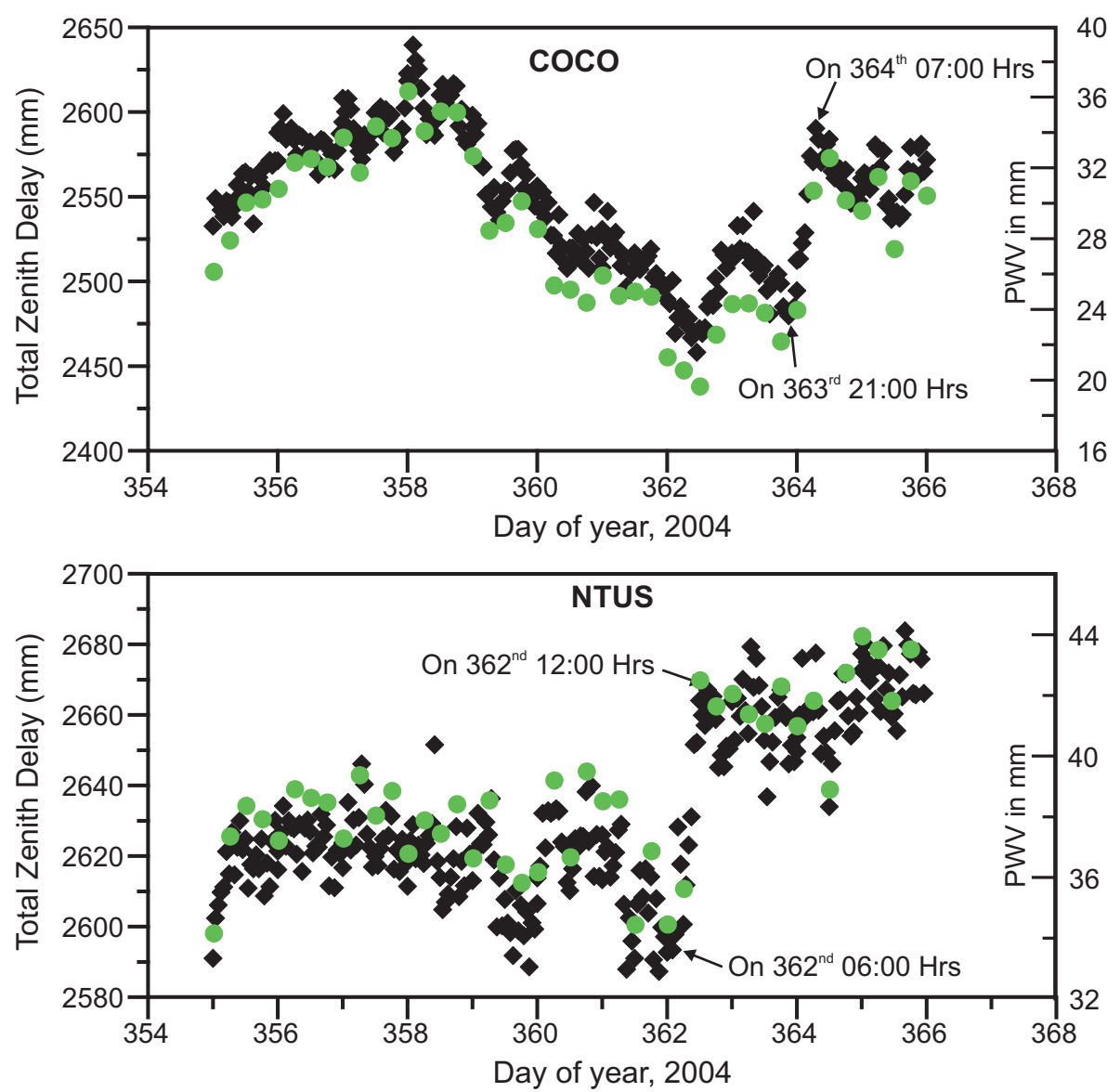

Figure 4. Total Zenith Delays (ZTD) observed (black diamond) at COCO (top) and NTUS (bottom) are shown with the estimated PWV values (green circles) during the 2004 great Sumatra earthquake event time. 


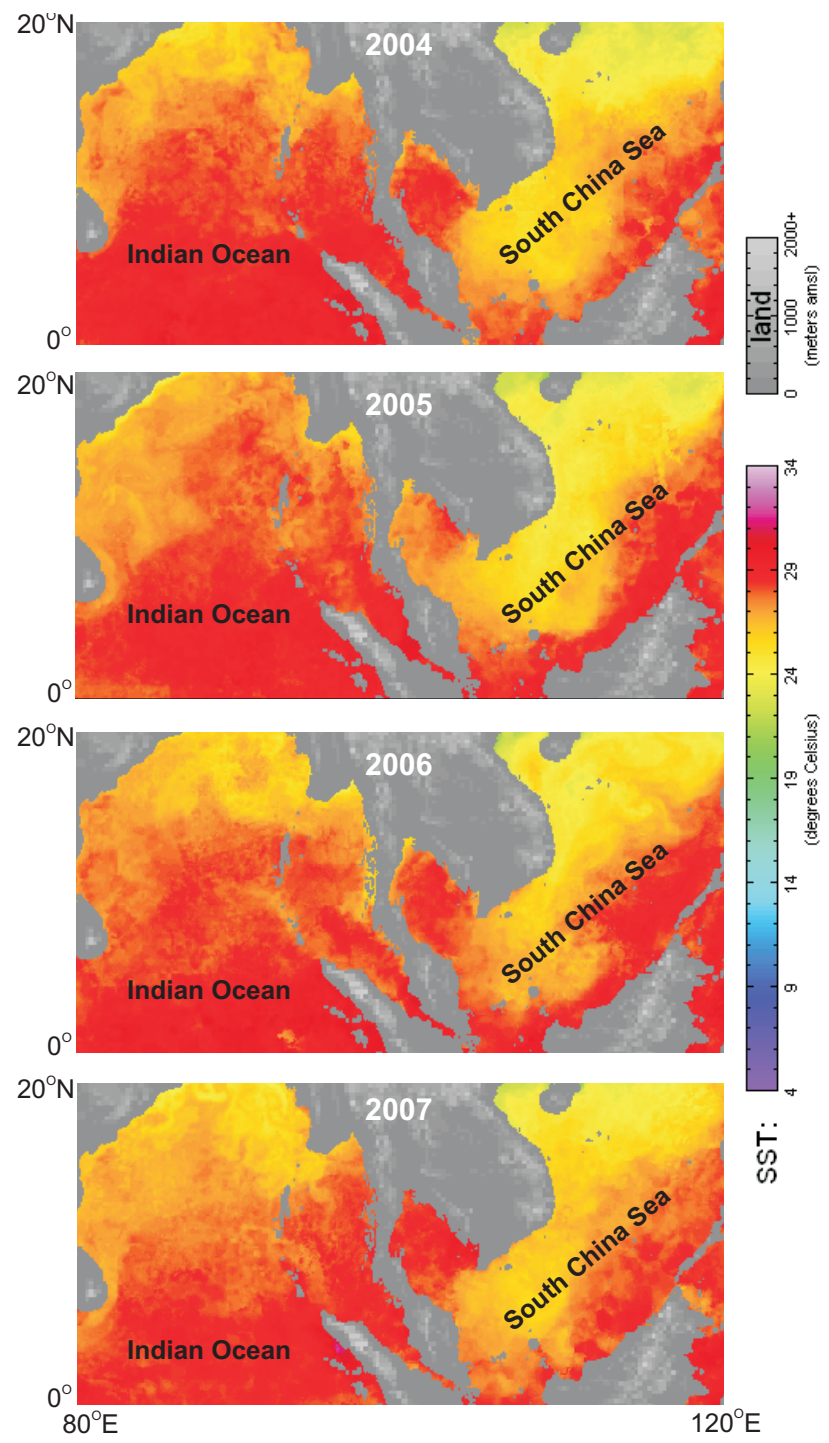

Figure 5. Sea surface temperature observed for the northern Indian Ocean region for the day of December 26 in 2004, 2005, 2006, and 2007. It can be noted from the figures that the Indian Ocean observed relatively hotter sea surface temperature conditions in the year 2004 than in the subsequent years.

through the magma upwelling processes (which is also cited as the cause of swarm activity in the region) might have caused increase in ocean water temperature and catalyzed the evaporation process. Such a mechanism could be the reason for the higher ZTD values noticed above COCO and NTUS stations. Higher sea surface temperature was measured in the Indian Ocean region during the occurrence of the main shock and this enhanced sea surface temperature condition was significant when compared to the 26th December day of the subsequent years (Figure 5). The eruption of mud volcano in the Baratang Island of the Andaman region immediately after the 2004 Sumatra earthquake [Mellors et al. 2007] supports the release of subsurface thermal onto the surface through magma movement and upwelling.

The average value of ZTD in the Indian Ocean re- gion during normal tropospheric condition is $\sim 2.37 \mathrm{~m}$ [Hogg et al. 1981]; a similar average ZTD value was also found during the periods of no major events in the region [Jade et al. 2005]. The mean value of ZTD in the close equatorial region is $\sim 2600 \mathrm{~mm}$ [Jin et al. 2007]. A significant change in ZTD was found during the occurrence of storms [Akilan et al. 2015], and also during the occurrence of earthquake swarms in the Andaman region [Akilan et al. 2017]. Akilan et al. [2017] analyzed different cyclonic storms originated in the Andaman Sea and Bay of Bengal and concluded that the higher ZTD and subsequent cyclonic conditions are associated to the earth geodynamic processes in the Andaman-Sumatra subduction zone, namely magma upwelling and seismicity. The higher water vapor precipitated in the atmosphere over the region found to be moved to the coasts, controlled by the direction of the turbulent atmosphere conditions which slowly transformed into cyclones, and made landfall at the coastal location resulting in heavy rainfall [Akilan et al. 2017]. In the case of Sumatra earthquake, no significant changes in ZTD values at the GPS locations, and no abnormal rainfall occurrence in the Indian Ocean region and Indian subcontinent situated west of the Sumatra earthquake zone (Figure 3) were observed. This means that the high water vapor formed over the Sumatra epicentral region did not move towards west, perhaps controlled by the atmospheric wind directions prevailed at that time.

The higher ZTD values noticed for NTUS and COCO sites suggest that most of the water vapor propagated towards to the east and some towards south of the earthquake location. The higher precipitation formed in the atmosphere over an area generally dissipates through rainfall in its surrounding region or far depending upon the atmospheric wind circulations. There were no reports of significant rainfall in the epicentral region and its surrounding regions, like the Indonesian Islands located near to the NTUS site, after the earthquake. This perhaps suggests that the higher PWV formation associated to the seismicity might have moved to far distance and may have made a landfall. It was noted that, during the main earthquake event and subsequent aftershock time, the subtropical jet stream was active in the region and moisture-laden storm systems moved off the Pacific Ocean towards the southern California coast from $27^{\text {th }}$ of December 2004 through $13^{\text {th }}$ of January 2005 (http: / /www.ncdc.noaa.gov/oa/climate/research $/ 2004 /$ california-storms2005.html). From $28^{\text {th }}$ of December 2004 to $12^{\text {th }}$ of January 2005, southern California has seen a series of heavy precipitation and experienced heavy rain and snow falls (http: / / www.ncdc.noaa.gov/oa/climate/re- 


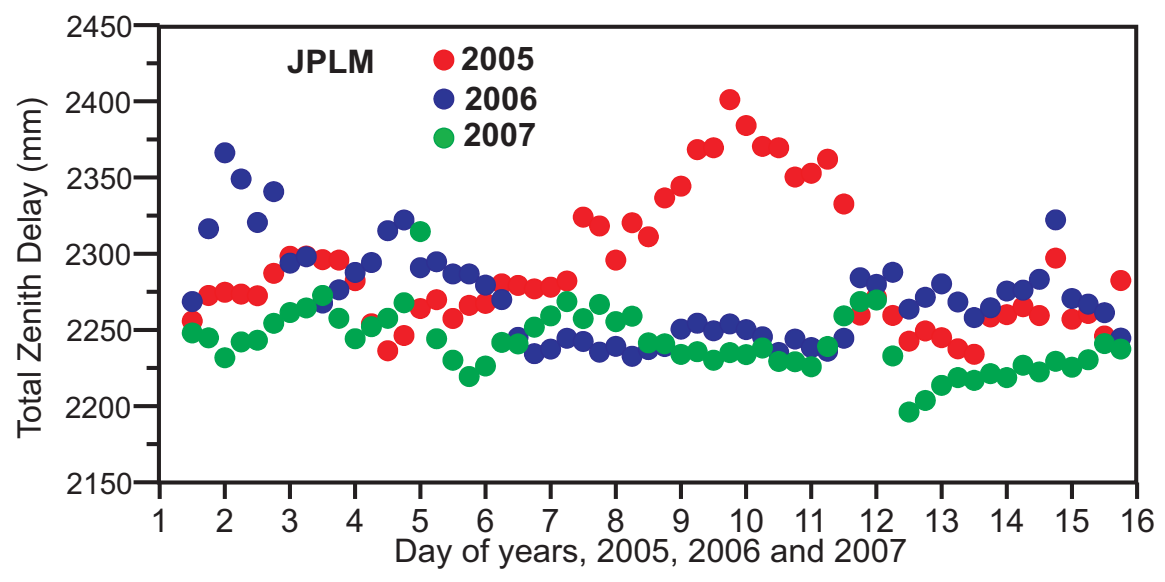

Figure 6. Comparison of Total Zenith Delays (ZTD) observed at JPLM site in California during the month of January 2005,2006 and 2007 years.

search/2004/california-storms2005.html). Figure 6 shows the ZTD values observed at the GPS site JPLM in the California coast, which illustrates the high precipitation level over the region after the Sumatra main earthquake and subsequent aftershock activities. The recorded heavy rainfall $(>700 \mathrm{~mm}$ ) was highest in the history of the region since records began in 1877 . The high precipitation anomaly in the year 2005 can be noticed from the comparison between the subsequent years, namely 2006 and 2007 (Figure 6). Such high precipitation in the winter period is unusual and it was inferred that the El Niño conditions in the Pacific Ocean do not appear to be the primary contributing factor for these precipitation events (http: / / www.ncdc.noaa.gov/oa/climate/ research/2004/california-storms2005.html). The resulted flood situation caused significant loss to human life and property [Carpenter et al. 2007].

\section{Conclusion}

We assessed the changes in atmospheric water vapor content produced by the great Sumatra earthquake of $26^{\text {th }}$ of December, 2004 at GPS locations around the earthquake epicentral zone. The ZTD experienced by the GPS signals, which are directly linked to the water vapor content in the atmosphere over the observation point, showed that significantly large increase in ZTD occurred at sites located to the east (NTUS) and to the south (COCO) of the epicentre, but no changes are seen towards the west. The higher precipitation levels formed after the seismic event did not lead to any rainfalls in the regions close to the epicentral zone. The absence of rain in the vicinity of earthquake zone and the active subtropical jet stream present over the region during this period suggested that perhaps the precipitated water formed in the atmosphere over the earthquake and surrounding might have moved to the east and passed to the southern California coast (from $27^{\text {th }}$ of December, 2004 through $13^{\text {th }}$ of January, 2005; http: / / www.ncdc.noaa.gov / oa / climate / research/2004/california-storms2005.html) by the eastward flow direction of the jet stream. At the same time, southern California experienced historical heavy rain and snow falls (http://www.ncdc.noaa.gov/oa/climate/ research/2004/ california-storms2005.html) from 28 th of December 2004 to $12^{\text {th }}$ of January, 2005. Since such high precipitation in the winter period is unusual and the El Nino conditions in the Pacific Ocean cannot explain the high precipitation levels during this time (http: / / www.ncdc.noaa.gov/oa/ climate/ research/2004/california-storms2005.html), the unusual weather conditions over the Californian coast might have been caused by transport of high water vapor formed over the Sumatra earthquake epicentral region to the California coast by the subtropical jet stream movement from west to east.

Acknowledgements. We thank Dr. V.M. Tiwari, Director, CSIR-NGRI for the permission to publish this work. The work has been carried out under the project ILP 0301-28 (KJC). This study used data from the IGS global data centre.

\section{References}

Afraimovich, E.L., N.P Perevalova., A.V Plotnikov and A.M Uralov (2001). The shock-acoustic waves generated by the earthquakes. Ann. Geophys., 19, 395-409.

Aki, K. (1971). Earthquake Mechanism, Tectonophysics., 13, 423-446.

Akilan, A., K.K. Abdul Azeez., S. Balaji., H. Schuh and Y. Srinivas (2015). GPS derived Zenith Total Delay (ZTD) observed at tropical locations in South India during atmospheric storms and depressions, Journal of Atmospheric and Solar-terrestrial Physics., 125-126, 1-7.

Akilan, A., K.K. Abdul Azeez., H. Schuh., S. Padhy and 
N. Subhadra (2016). Changes in atmospheric water content associated to an unusual high snowfall during June 2004 at Maitri station (Schirmacher Oasis, East Antarctica) and the role of south-west Indian ridge geodynamics, Natural Hazards., 83, 563-574.

Akilan, A., K.K. Abdul Azeez and H. Schuh (2017). Atmospheric storm triggered and Intensified by Geodynamics: Case studies from Andaman Sea and Bay of Bengal region in the Indian Ocean, Pure and Applied Geophysics., 174, 2173-2194.

Ammon, C.J., C. Ji., H.K. Thio., D. Robinson., S. Ni., V. Hjorleifsdottir., H. Kanamori., T. Lay., S. Dus., D. Helmberger., G. Ichinose., J. Polet and D.Wald (2005). Rupture process of the 2004 Sumatra-Andaman earthquake, Science., 308,1133-1139.

Bevis, M., S. Businger., T.A. Herring., C. Rocken., R.A. Anthes and R.H. Ware (1992). GPS Metrology: Remote sensing of atmospheric water vapour using the global positioning system, Journal of Geophysical Research., 97, 15787-15801.

Bock, O., P. Willis., W. Junhong., and C. Mears (2014). A high-quality, homogenized, global, long-term (1993-2008) DORIS precipitable water data set for climate monitoring and model verification, J. Geophys Res., doi: 10.1002/2013JD021124.

Boehm, J., B. Werl., and H. Schuh (2006). Troposphere mapping function for GPS and VLBI from ECMWF operational analysis data, J. Geophys Res., doi: 10.1029/2005JB003629.

Burgmann, R., P.A. Rosen and E.J. Fielding (2000). Synthetic Aperture Radar Interferometry to measure Earth's surface topography and its deformations, Ann. Rev. Earth Planet. Sci., 28, 169-209.

Businger, S., S.R. Chiswell., M. Bevis., J. Duan., R.A. Anthes., C. Rocken., R.H. Ware., M. Exner., T. Van Hove and F.S. Solheim (1996). The promise of GPS in Atmospheric Monitoring, Bulletin of the American Meteorological Society., 77, 5-17.

Calais, E and J.B. Minister (1995). GPS detection of ionospheric perturbations following the January 17, 1994, Northridge earthquake, Geophys. Res. Lett., 22,1045-1048.

Carpenter, T.M., J. Wang., S.V. Taylor., E. Shamir., J.A. Sperfslage and K.P. Georgakakos (2007). Surveying flash flood response in mountain streams, EOS transactions., 88, 69-80.

Catherine, J.K., D.U. Maheshwari., V.K. Gahalaut, P.N.S. Roy., P.K. Khan and N. Puviarasan (2017). Ionospheric disturbances triggered by the 25 April, 2015 M7.8 Gorkha earthquake, Nepal: Constraints from GPS TEC measurements, Journal of Asian Earth Sciences., 133, 80-88.
Dach, R., U. Hugentobler., P. Fridez and M. Meindl (2007). Bernese GPS Software Version 5.0. Astronomical Institute, University of Bern.

Ducic, V., J. Artru and P. Lognonne (2003). Ionospheric remote sensing of the Denali earthquake Rayleigh surface waves, Geophys. Res. Lett., 30, 1951, http: / / dx.doi.org/10.1029/2003GL017812.

Hogg, D.C., F.O. Guiraud and F.T. Decker (1981). Measurement of excess transmission length space paths, Astronomy and Astrophysics., 95,304-307.

Heki, K. (2011). Pre-seismic TEC increase above the focal region of the 2011 Tohoku Earthquake: the best recorded earthquake precursor in the history, AOGS, 8-12 Aug 2011 Taipei, Taiwan.

Heki, K and Y. Enomoto (2013). Preseismic ionosphere electron enhancements revisited, Journal Geophysical Research., 118, 6618-6626.

Jade, S., M.S.M. Vijayan., V.K. Gaur., T.P. Prabhu and S.C. Sahu (2005). Estimates of precipitable water vapour from GPS data over the Indian subcontinent, Journal of Atmospheric and Solar terrestrial Physics., 67, 623-635.

Jin, S., J-U. Park., J-H. Cho and P.H. Park (2007). Seasonal variability of GPS-derived zenith troposphere delay (1994-2006) and climate implications, Journal of Geophysical Research., 112, doi: 10.1029/2006JD007772.

Karpin, T.L and C.H. Thurber (1987). The relationship between earthquake swarms and Magma transport: Kilauea Volcano Hawaii, PAGEOPH., 125, 971-991.

Kundu, B., D. Legrand., K. Gahalaut., V.K. Gahalaut., P. Mahesh., K.A. Kamesh Raju., J.K. Catherine., A. Ambikapathy and R.K. Chadha (2012). The 2005 volcano-tectonic earthquake swarm in the Andaman Sea: Triggered by the 2004 great SumatraAndaman earthquake, Tectonics., 31, TC5009, doi:10.1029/2012TC003138.

Larson, K.M., P. Bodin and J. Comberg., (2003). Using 1$\mathrm{Hz}$ GPS data to measure deformations caused by the Denali fault earthquake, Science., 300, 1421-1424.

Larson, K.M. (2009). GPS Seismology, J. Geod., 83, 227233.

Leick, A. (1990). GPS satellite surveying. John Wiley and Sons, 352pp.

Liu, J.Y., H.F. Tsai., C.H. Lin., M., Kamogawa., Y.I. Chen., C.H. Lin., B.S. Huang., S.B. Yu and Y.H. Yeh (2010). Cosesismic ionospheric disturbances triggered by the Chi-Chi earthquake, J. Geophys. Res., 115, A08303, http: / / dx.doi.org/10.1029/2009JA014943

McNamara, D.E., W.L. Yeck., W.D. Barnhart, V. Schulte-Pelkum., E. Bergman., L.B. Adhikari., A. Dixit., S.E. Hough., H.M. Benz and P.S. Earle (2016). 
Source modelling of the $2015 \mathrm{Mw} 7.8$ Nepal (Gorkha) earthquake sequence: Implications for geodynamics and earthquake hazards, Tectonophyics., http: / / dx.doi.org/20.1016/j.tecto.2016.08.004

Mellors, R., D. Kilb., A. Aliyev., A. Gasanov and G. Yetirmishli (2007). Correlations between earthquakes and large mud volcano eruptions, Journal of Geophysical Research., 112, doi: 10.1029/2006JB004489.

Nilsson, T., J. Böhm., D.D. Wijaya., A. Tresch., V. Nafisi and H. Schuh (2013). Path delays in the neutral atmosphere, in: J. Böhm, H. Schuh (Eds.), Atmospheric Effects in Space Geodesy. Springer-Verlag Berlin Heidelberg., doi: 10.1007/978-3-642-36932-2_3.

Nilsson, T and Elgered, G (2008). Long-term trends in the atmospheric water vapour content estimated from ground-based GPS data, Journal of Geophysical Research., 113, D19101, doi: 10.1029/2008JD010110.

Ohta, Y., I. Meilano., T. Sagiya., F. Kimata and K. Hirahara (2006). Large surface wave of the 2004 Sumatra-Andman earthquake captured by the very long baseline kinematic analysis of 1-Hz GPS data, Earth Planets Space., 58, 153-157.

Ouzounov, D and Freund, F (2004). Mid-infrared emission prior to strong earthquakes analysed by remote sensing data, Advances in space research., 33, 268-273.

Ouzounov, D., S. Pulinets and M. Kafatos (2011). Rapid transient phenomena in atmosphere ionosphere associated with the March 11th 2011 M9 Tohoku earthquake, observed by joint space and ground observation. AOGS, 8-12 Aug 2011, Taipei, Taiwan.

Paul, J., A.R. Lowry., R. Bilham., S. Sen and JrR. Smalley (2007). Post seismic deformation of the Andaman Islands following the 26 December, 2004 Great Sumatra-Andaman earthquake. Geophysical Research Letters., 34, doi: 10.1029/2007GL031024.

Pulinets, S.A., D. Ouzounov., A.V. Karelin., K.A. Boyarchuk and L.A. Pokhmelnykh, (2003). The physical nature of thermal anomalies observed before strong earthquakes, Physics and Chemistry of the Earth., 31, 143-153.

Saraf, A.K and S. Choudhury (2005). Thermal remote sensing technique in the study of pre-earthquake thermal anomalies, Journal of Indian Geophysical Union., 9, 197-207.

Tronin, A.A., M. Hayakawa and O.A. Molchanov (2002). Thermal IR satellite data application for earthquake research in Japan and China, Journal of Geodynamics., 33, 519-534.

Vigny, C., W.J.F. Simons., S. Abu., R. Bamphenyu., C. Satirapod., N. Choosakul., C. Subarya., A. Socquet.,
K. Omer., H.Z. Abidin and B.A.C. Ambrosius (2005). Insight into the 2004 Sumatra-Andaman earthquake from GPS measurements in Southeast Asia, Nature., 436, 201-206.

Walter, T.R and F. Amelung (2007). Volcanic eruption following $M \geq 9$ megathrust earthquakes: Implications for the Sumatra-Andaman volcanoes, Geology., 35, 539-542.

Wang, H., M. Wei., G. Li., S. Zhou and Q. Zeng (2013). Analysis of precipitable water vapour from GPS measurements in Chengdu region: Distribution and evolution characteristics in autumn, Advances in Space Research., 52, 656-667.

Yuan-Sheng, Z., G. Xiao., W. Cong-Xin., S. Wen-Rong and H. Shao-Xing (2011). Characteristics of seismic thermal radiation of the Japan Ms9.0 and Myanmar Ms7.2 earthquake, Chinese Journal of Geophysics., 54, 670-676.

\footnotetext{
*Corresponding author: Athiswamy Nadar Akilan, CSIR-National Geophysical Research Institute, Hyderabad, India;
} email: akilan@ngri.res.in.

(C) 2018 by the Istituto Nazionale di Geofisica e Vulcanologia. All rights reserved. 